\title{
Behavioral changes before metritis diagnosis in dairy cows
}

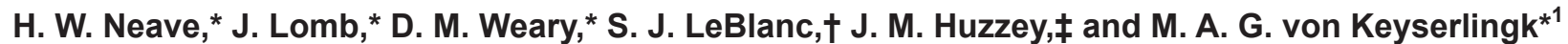 \\ *Animal Welfare Program, Faculty of Land and Food Systems, University of British Columbia, Vancouver, British Columbia, Canada, V6T 1 Z4 \\ †Department of Population Medicine, University of Guelph, Guelph, Ontario, Canada, N1G 2W1 \\ ‡Department of Animal Science, California Polytechnic State University, San Luis Obispo 93407
}

\begin{abstract}
Metritis is common in the days after calving and can reduce milk production and reproductive performance. The aim of this study was to identify changes in feeding and social behavior at the feed bunk, as well as changes in lying behavior before metritis diagnosis. Initially healthy Holstein cows were followed from $3 \mathrm{wk}$ before to 3 wk after calving. Behaviors at the feed bunk were recorded using an electronic feeding system. Lying behavior was recorded using data loggers. Metritis, based upon the characteristics of vaginal discharge at d 3, 6, 9, 12 and 15 after calving, was diagnosed in 74 otherwise healthy cows. Behavior of these cows, beginning 2 wk before calving until the day of diagnosis, was compared with 98 healthy cows (never diagnosed with any health disorder, including ketosis, mastitis, and lameness) during the transition period. During the 2 wk before calving, cows later diagnosed with metritis had reduced lying time and fewer lying bouts compared with healthy cows. In the $3 \mathrm{~d}$ before clinical diagnosis, cows that developed metritis ate less, consumed fewer meals, were replaced more often at the feed bunk, and had fewer lying bouts of longer duration compared with healthy cows. We concluded that changes in feeding as well as social and lying behavior could contribute to identification of cows at risk of metritis.
\end{abstract}

Key words: sickness behavior, social competition, animal welfare, precision farming

\section{INTRODUCTION}

During the transition period, characterized as the 3 wk before and after calving, the dairy cow must cope with changes in energy demand as a result of fetal growth and the onset of lactation, which consequently increases the risk of metabolic illnesses and the risk of infection through the vaginal canal and teat ends

Received April 25, 2017.

Accepted July 6, 2017.

${ }^{1}$ Corresponding author: marina.vonkeyserlingk@ubc.ca
(LeBlanc, 2010). The combined effects are such that the majority of health disorders are diagnosed in the month following calving, reducing milk production and reproductive performance and increasing culling rate (Esposito et al., 2014).

Changes in feeding behavior around calving can identify cows at risk for postpartum health disorders. For example, decreased feed intake, feeding time, and feeding rate have been observed in the $3 \mathrm{~d}$ before ketosis diagnosis (González et al., 2008). Some studies have shown changes in these behaviors prepartum can be predictive of postpartum health disorders. For example, Urton et al. (2005) and Huzzey et al. (2007) found that cows with lower feeding times and intakes in the weeks before calving were more likely to be diagnosed with metritis after calving.

Few studies have reported changes in meal frequency or meal duration in relation to health disorders. Parasitized cattle tended to have reduced meal frequency 7 wk after infection (Szyszka et al., 2013) and meal duration increased following anthelmintic treatment (Forbes et al., 2004). Cows decreased the number of meals per day before they were identified as lame (González et al., 2008) and as they became lame (Bach et al., 2007). It follows that meal frequency and duration may be expected to decline in cows with health disorders during the transition period.

Social behaviors, typically reported as competitive interactions or displacements at the feed bunk, are also a promising early indicator of illness (Proudfoot et al., 2012). Displacements are typically recorded using either video or live observation of animals, but both methods are time consuming. Data from an electronic feeding system can be used for automated identification of competitive replacements at feed bins (Huzzey et al., 2014). To date, 2 studies have used this method to examine social competition in relation to cow health (Sepúlveda-Varas et al., 2014; Schirmann et al., 2016).

Several studies have investigated changes in lying behavior as an indicator of ill health. For example, cows diagnosed with ketosis after calving stood longer before and during calving and changed from standing to lying less often on the day of calving (Itle et al., 
2015). A small study of prepartum behaviors of crossbred cows housed in paddocks found no difference in standing time or standing bouts between healthy cows and metritic cows after calving, but metritic cows spent more time standing inactive (Patbandha et al., 2012). Sepúlveda-Varas et al. (2014) reported longer lying times and a tendency of longer lying bouts for grazing primiparous dairy cows that were diagnosed with more than 1 clinical health disorder.

Studies have reported behavioral changes relative to day of diagnosis for mastitis (Sepúlveda-Varas et al., 2016) and ketosis (González et al., 2008), but this has yet to be documented for metritis. Metritis is typically diagnosed in the first 2 or 3 wk after calving (Sheldon et al., 2006, 2008). To our knowledge, no study has investigated whether behavior differs depending on when metritis is diagnosed.

The objectives of our study were to identify changes in lying, feeding, and social behavior in the days before diagnosis of metritis, and to describe how behavioral changes relate to the day of diagnosis. This study also served to build upon the findings of a previous study (Huzzey et al., 2007) that described changes in prepartum feeding behavior of cows subsequently diagnosed with metritis. Because Huzzey et al. (2007) did not exclude ketotic cows in their study, we speculated that behavioral differences from healthy cows might be driven by the presence of both metritis and subclinical ketosis; thus, we also included subclinically ketotic animals in a secondary analysis.

\section{MATERIALS AND METHODS}

\section{Animals, Housing, and Diet}

All cows in our study were cared for under the Canadian Council of Animal Care guidelines (CCAC, 2009), and all procedures were approved by the UBC Animal Ethics Committee (Protocol A14-0040). All cows enrolled in the current study were a convenience sample from the herd at the University of British Columbia's Dairy Education and Research Center in Agassiz, British Columbia, Canada. This study used the same population of animals reported in Neave et al. (2017), and the same animals that were enrolled in a study investigating the effects of nonsteroidal anti-inflammatory drug administration following metritis diagnosis (Lomb et al., 2018).

Our target sample size was 90 metritic cows, chosen to achieve the primary objective of the nonsteroidal anti-inflammatory drug administration study [data from Huzzey et al. (2007) showed that 45 cows per treatment group were required to detect a difference of $1.7 \mathrm{~kg} / \mathrm{d}$ of DMI $(\mathrm{SD}=2.9)$ or $25 \mathrm{~min} / \mathrm{d}$ of feeding time $(\mathrm{SD}=$ 40) between treatment groups; power $=0.80 ; \alpha=0.05]$. Based upon expected rates of metritis, we followed a total of 337 Holstein dairy cows, 105 primiparous (i.e., never previously calved) and 232 multiparous (average parity $1.8 \pm 1.9$ (SD); range of 0 to 8 lactations]. Cows were enrolled in the study 3 wk before expected calving between July 2013 and November 2014. Cows were not enrolled if their gait score was $>3$ (following Flower and Weary, 2006) in the week before enrollment in the study.

Cows were housed in prepartum and postpartum group pens equipped with 12 Insentec (Insentec, Marknesse, the Netherlands) feed bins and 2 Insentec water troughs. Each pen was equipped with 24 freestalls (2.6 $\times 1.2 \mathrm{~m}$; neck rail positioned $1.2 \mathrm{~m}$ above the stall surface) separated by Y2K freestall partitions (Artex, Langley, BC, Canada), and each stall was fitted with a mattress (Pasture Mat, Promat Inc., Woodstock, ON, Canada) covered with $5 \mathrm{~cm}$ of sand bedding. Stocking density in the pens was maintained at 20 cows per pen and group composition was dynamic depending on expected and actual calving dates. Cows were moved into the prepartum pen approximately 3 wk before their expected calving date and then moved to the maternity pen when they showed signs of calving (checked twice during the day and once at $2200 \mathrm{~h}$ for tense and enlarged udder, relaxed pelvic ligaments, or raised tail; Proudfoot et al., 2013). The maternity pen contained a sawdust-bedded pack with 6 Insentec feed bins and 1 Insentec water trough. A maximum of 2 cows were kept in the maternity pen at any given time. Within $24 \mathrm{~h}$ after calving, cows were moved to the postpartum pen and monitored for a further 3 wk. Postpartum cows were milked twice per day at approximately 0700 and $1700 \mathrm{~h}$ in a double 12 parallel milking parlor; waiting time in the holding area before milking did not exceed 30 min per milking.

Pre- and postpartum groups were fed a TMR at approximately 0800 and $1600 \mathrm{~h}$. Feed samples were collected weekly and then pooled into monthly samples. Samples were dried at $60^{\circ} \mathrm{C}$ for $48 \mathrm{~h}$ to determine $\mathrm{DM}$ content and sent for nutrient analysis (A\&L Canada Inc., London, ON, Canada). Before calving, cows were fed a TMR consisting of $32 \%$ corn silage, $37 \%$ alfalfa hay, $18 \%$ ryegrass straw, and $13 \%$ grain concentrate mash $(\mathrm{DM}=52.4 \pm 4.7 \%, \mathrm{CP}=14.3 \pm 0.34 \% \mathrm{DM}$, $\mathrm{ADF}=34.6 \pm 0.60 \% \mathrm{DM}, \mathrm{NDF}=46.5 \pm 0.17 \% \mathrm{DM}$, and $\mathrm{NE}_{\mathrm{L}}=1.39 \pm 0.0071 \mathrm{Mcal} / \mathrm{kg}$ ). After calving, cows were fed a TMR consisting of $26 \%$ corn silage, $13 \%$ grass silage, $7 \%$ alfalfa hay, $4 \%$ grass hay, and $50 \%$ grain concentrate mash $(\mathrm{DM}=50.35 \pm 2.5 \%, \mathrm{CP}=$ $18.3 \pm 0.58 \% \mathrm{DM}, \mathrm{ADF}=18.1 \pm 0.71 \% \mathrm{DM}, \mathrm{NDF}=$ $28.5 \pm 1.2 \% \mathrm{DM}$, and $\left.\mathrm{NE}_{\mathrm{L}}=1.72 \pm 0.014 \mathrm{Mcal} / \mathrm{kg}\right)$. 
Diets were formulated according to the NRC (2001) to meet or exceed the requirements of a $620-\mathrm{kg}$ Holstein cow producing $40 \mathrm{~kg} / \mathrm{d}$ of $3.5 \%$ FCM.

\section{Health Assessment}

For the remainder of this paper, we use the terminology metritic to refer to cows diagnosed with metritis, and sick to refer to cows diagnosed with an illness other than metritis or more than 1 illness. After calving, cow health was monitored for $21 \mathrm{~d}$ by researchers, the farm staff, and the herd veterinarian. Cows that did not develop any clinical health disorder within $21 \mathrm{~d}$ were considered healthy. Cows were screened for metritis on $\mathrm{d} 3$, $6,9,12$, and 15 postpartum. Vaginal discharge was assessed by inserting a gloved hand into the vaginal canal up to the cervix and taking a sample of the discharge. The appearance and smell of the discharge was evaluated and assigned a score based on the system used by Urton et al. (2005) and Huzzey et al. (2007), where no mucus or clear mucus $=0$; red or brown mucus, cloudy mucus, or mucus with flecks of pus without foul smell = 1 ; mucopurulent ( $\leq 50 \%$ pus present) and foul smelling $=2 ;$ purulent $(\geq 50 \%$ pus present $)$ and foul smelling $=$ 3 ; and putrid (red or brown color, watery, foul smelling) $=4$. Cows were classified as having metritis if they had at least one discharge score of 2,3 or 4 . Cows diagnosed with metritis were administered ceftiofur $(2.2 \mathrm{mg} / \mathrm{kg}$ of BW s.c.; Excenel RTU sterile suspension, $50 \mathrm{mg} /$ $\mathrm{mL}$ as ceftiofur hydrochloride, Zoetis, Parsippany, NJ) injected once daily after the morning milking beginning on the day of diagnosis for 5 consecutive days. As part of enrollment in a secondary study (Lomb et al., 2018), metritic cows were also administered a single dose (0.5 $\mathrm{mg} / \mathrm{kg}$ s.c. in the neck region) of either meloxicam (Metacam $20 \mathrm{mg} / \mathrm{mL}$ solution, Boehringer Ingelheim GmbH, Ingelheim am Rhein, Germany) or a placebo solution (Boehringer Ingelheim $\mathrm{GmbH}$ ). After diagnosis and initiation of treatment of metritis, cows were reexamined for metritis every $3 \mathrm{~d}$ until $21 \mathrm{~d}$ after calving. Rectal temperatures were taken daily after the morning milking and before noon using a digital thermometer (Nexcare Rapid Digital Thermometer, 3M, St. Paul, $\mathrm{MN})$. Preliminary analysis of behaviors revealed no difference between metritic cows with and without fever, so fever was not included as a diagnostic criterion.

Cows were screened for mastitis twice per day by farm staff during the morning and afternoon milkings. Mastitis was diagnosed based on the presence of clots in the milk or a red, swollen, or hard quarter. Cases of other clinical health disorders, including ketosis, down-cow syndrome, and displaced abomasum, were diagnosed by the farm staff or herd veterinarian. Ke- tosis was diagnosed based on a low feed intake or a drop in milk production and confirmed with a milk BHB acid test strip result $\geq 100 \mu \mathrm{mol} / \mathrm{L}$ (KetoTest, Elanco Animal Health, Nagoya, Japan). Cows that had a marked reduction in feed intake during the previous day were examined by a veterinarian for displaced abomasum and were diagnosed based on auscultation of a characteristic tympanic resonance during percussion on the left side. Cows that were unable to stand despite treatment for clinical hypocalcemia were considered as having down-cow syndrome.

Blood was drawn from the coccygeal vessels into 10-mL sterile tubes coated with sodium heparin (BD Vacutainer, Franklin Lakes, NJ) at the time of metritis examination on d 3, 6, and 12 after calving. Plasma was collected via centrifugation $(2,800 \times g$ for $15 \mathrm{~min}$ at $4^{\circ} \mathrm{C}$ ) and stored at $-20^{\circ} \mathrm{C}$ until processing at the University of Guelph Animal Health Laboratory (Guelph, ON, Canada) using the Randox BHB test kit (Randox Laboratories Canada Ltd., Mississauga, ON, Canada) on a Roche Cobas auto-analyzer (Roche Diagnostics, Indianapolis, IN).

\section{Cow Participation in Study}

A total of 117 cows were excluded from the final analysis due to postpartum illnesses, including cows with mastitis $(\mathrm{n}=9)$, clinical ketosis $(\mathrm{n}=2)$, downcow syndrome $(\mathrm{n}=3)$, displaced abomasum $(\mathrm{n}=6)$, lameness (gait score $>3 ; n=10)$, dystocia ( $\geq 2$ people required during assisted calving; $\mathrm{n}=13$ ), cows that received 2 or more drenches $(\mathrm{n}=9)$, more than $2 \mathrm{~d}$ of fever without metritis $(\mathrm{n}=12)$, or combinations of the above $(\mathrm{n}=53)$. A further 19 cows were excluded from the study due to incomplete electronic data prepartum (due to early calving) or postpartum (due to space constraints requiring that the animal be moved from the test pen). Of the remaining cows, 15 otherwise clinically healthy cows were excluded due to subclinical ketosis (blood BHB >1.2 mmol/L found during routine screening as described above; Työppönen and Kauppinen, 1980; LeBlanc, 2010).

The final analyses included 74 cows with only metritis (44 primiparous and 30 multiparous cows), diagnosed with metritis on d 3 (score $4, \mathrm{n}=7$ ), 6 ( (score $3, \mathrm{n}=$ 4 ; score $4, \mathrm{n}=28), 9($ score $3, \mathrm{n}=5$; score $4, \mathrm{n}=11)$, 12 (score $3, \mathrm{n}=4$; score $4, \mathrm{n}=7$ ), or 15 (score $2, \mathrm{n}=$ 2 ; score $3, \mathrm{n}=6$ ) after calving. No cows with metritis score 3 were diagnosed on d 3 and no cows with metritis score 4 were diagnosed on d 15 . Because few cows were scored $2(n=2)$, these animals were combined with cows scored 3 and hereafter are referred to as score 3 . An additional 12 cows diagnosed with metritis 
(score $3, \mathrm{n}=2$; score $4, \mathrm{n}=10$ ) were also classified as subclinically ketotic (blood $\mathrm{BHB}>1.2 \mathrm{mmol} / \mathrm{L}$ ) and were included in a separate analysis (i.e., a total of 86 cows with either metritis only or metritis and subclinical ketosis). The 38 healthy primiparous and 62 healthy multiparous cows were the same animals described in our earlier analysis of parity effects (Neave et al., 2017).

Body weight was determined by averaging 2 measurements taken on 2 consecutive days after calving (d 21-23). Postpartum BW averaged (mean \pm SD) $556 \pm 46.0 \mathrm{~kg}$ for primiparous and $674 \pm 54.7 \mathrm{~kg}$ for multiparous cows and did not differ between the health categories. Average daily milk production $($ mean \pm SD) over the first $21 \mathrm{~d}$ after calving averaged $23.3 \pm 4.2 \mathrm{~L} / \mathrm{d}$ for primiparous cows and $33.4 \pm 4.5 \mathrm{~L} / \mathrm{d}$ for multiparous cows and did not differ between health categories.

\section{Behavioral Data Collection}

The Insentec electronic feed-monitoring system recorded feeding and social behavior at the feed bunk for the duration of the experimental period [see Chapinal et al. (2007) for a full description of this system]. Feed intake, feeding time, and visits and were calculated automatically by the Insentec system; a visit to the feed bin was recorded each time the cow arrived at and left the feed bin. Additional measures of feeding behavior were calculated using the data derived from the Insentec system, including feed consumption rate (DMI in $\mathrm{g} / \mathrm{min}$ ), number of meals, and number of bins visited within a meal. Dry matter intake was also considered as a percentage of BW, but these results did not differ from the unadjusted DMI values; therefore, we report unadjusted values below. Meal-based estimates of feeding behavior rely on the use of a meal criterion, which is defined as the minimum time interval between visits to consider the next visit to the bin as being part of a new meal. Meals were classified as being separated by 16.7min intervals before calving and by 20.1-min intervals after calving, as described by Proudfoot et al. (2009). These criteria were used to calculate meal frequency per day by counting the number of intervals between visits to the feed alley that exceeded the criterion and adding 1.

Competitive interactions at the feed bins were estimated based on a replacement criterion described by Huzzey et al. (2014). This approach is based on the principle that a short interval $(<26 \mathrm{~s})$ between successive feeding events of 2 cows at 1 feed bin is associated with a competitive replacement, where 1 cow (defined as the actor) makes physical contact with a feeding cow (defined as the reactor) and then takes her position at the bin. The number of actor replacement events (the number of times a cow was the actor in displacing a cow from the feed bin) and reactor replacement events (the number of times a cow was the reactor at the feed bin) were calculated separately. Given that a cow must be present at the feed bin to be involved in a replacement, we reported the number of replacements as a ratio of the number of visits to the feed bin per day (number of actor or reactor replacements/total number of visits).

Lying behaviors were recorded using data loggers (HOBO Pendant G Acceleration Data Logger, Onset Computer Corporation, Pocasset, MA) attached to the medial side of 1 hind leg of the cow using Vet Wrap (Co-Flex, Andover Coated Products Inc., Salisbury, MA). Loggers were changed and placed on alternating legs each week. Before calving, data for days on which loggers were changed were discarded due to incomplete data for that day. After calving, to avoid data loss while changing out the logger, a new data logger was attached during the morning milking and the previous logger was removed during afternoon milking, resulting in overlapping data that allowed for use of data for all postcalving days. At 1-min intervals, the g-forces of the $\mathrm{y}$ - and $\mathrm{z}$-axis were recorded and the data were processed using an adjusted version of the SAS algorithm developed by the UBC Animal Welfare Program (2013). The algorithm was adjusted for using histogram analysis of raw HOBO data, as described by Zobel et al. (2015), and for analysis of overlapping data on days of logger change. Measures of lying behavior included total lying time per day (min), number of bouts per day, and mean daily bout duration (min/bout).

\section{Statistical Analysis}

All statistical analyses were performed in SAS (version 9.4; SAS Institute Inc., Cary, NC). Complete feeding and social behavior data were available for all cows from $14 \mathrm{~d}$ before calving to $21 \mathrm{~d}$ after calving. The UNIVARIATE procedure was used to generate probability distribution plots; extreme outliers in feeding behavior (3 interquartile ranges beyond the first or third quartile of the data set) were considered to be the result of feed bin malfunctioning and were removed.

Accurate estimates of lying behavior require at least $3 \mathrm{~d}$ of consecutive observations (Ito et al., 2009). Thus, for this analysis, healthy cows that had missing data on 1 of the $3 \mathrm{~d}$ before each diagnosis day were excluded for that period $(\mathrm{d} 3: \mathrm{n}=25 ; \mathrm{d} 6: \mathrm{n}=12 ; \mathrm{d} 9: \mathrm{n}=11 ; \mathrm{d} 12$ : $\mathrm{n}=7 ; \mathrm{d} 15: \mathrm{n}=5)$. Four metritic cows diagnosed on $\mathrm{d}$ $3(n=1), 6(n=2)$, or $9(n=1)$ were excluded due to incomplete data for their respective $3 \mathrm{~d}$ before diagnosis. For the prepartum period, cows with fewer than 3 consecutive days in either wk -2 or -1 were excluded 
(healthy: $\mathrm{n}=7$; metritic score $4: \mathrm{n}=9$ ). Data loss was due to malfunction of the loggers or logger change.

Differences in feeding behavior (DMI, feeding time, feed bin visits, feeding rate, and number of meals), social behavior (replacement events), and lying behavior (total time, number of bouts, and average bout duration) between healthy and metritic cows during prepartum and the $3 \mathrm{~d}$ before diagnosis were analyzed separately. Healthy cows were not pair-matched to metritic cows; instead, metritic cows diagnosed on each of d 3, 6, 9, 12 , and 15 after calving were compared with all healthy cows on these same $5 \mathrm{~d}$ relative to calving, and analyses were controlled for parity.

Prepartum behavioral measures were summarized into 2 weekly periods, wk $-2(\mathrm{~d}-14$ to -8$)$ and wk -1 (d -7 to -1 ), and compared between healthy, metritic only, and metritic or metritic plus subclinically ketotic cows by week in a mixed model using PROC MIXED with the fixed effects of health (healthy, metritis score 3 or metritis score 4) and parity (primiparous or multiparous).

During the postpartum period, we expected changes in behavioral measures from the time of the previous metritis examination (when the cow was diagnosed as healthy) to the next examination $3 \mathrm{~d}$ later, at which the cow was diagnosed with metritis; thus, we focused our postpartum analysis on the 3 -d interval between metritis checks, d 0 to 2,3 to 5,6 to 8,9 to 11 , and d 12 to 14 for diagnosis on d 3,6,9, 12, or 15 after calving, respectively. Healthy cows were compared with metritic only and metritic or metritic plus subclinically ketotic cows within each of these periods in a repeated measures mixed model using PROC MIXED with the fixed effects of health (healthy, metritis score 3 or 4), parity (primiparous or multiparous), diagnosis day (continuous variable), and the interaction of health with diagnosis day. Interaction terms were dropped from the final model if $P>0.1$.

For both prepartum and postpartum analyses, we hypothesized that there would be differences between healthy and metritic animals. We first tested for differences between cows with metritis score 3 and 4 using a contrast statement. As we found no differences in any of the outcome measures, we combined metritic cows to test for differences between healthy and metritic cows. In addition, we tested for differences between healthy cows and those cows diagnosed with metritis only, and between healthy cows and those with metritis or metritis and subclinical ketosis. We did not have a specific hypothesis about behavioral changes on $\mathrm{d} 3,6,9,12$, or 15 ; rather, these days were selected as a logistical consideration to manage the work of the study. Therefore, we treated the day of diagnosis as continuous variable in postpartum analyses and predicted a linear decrease in behavior change as day of diagnosis increased after calving. For all models, cow was specified as the experimental unit with an autoregressive covariance structure. Results are reported as least squares means and SE for each prepartum week and for the $3 \mathrm{~d}$ before diagnosis. We also report the $F$-statistic and degrees of freedom in the format $F_{\text {(between-group df, within-group df). The }}$ interaction of health with diagnosis day is reported when significant. Significance was set at $P \leq 0.05$ and tendency at $0.05<P \leq 0.1$.

\section{RESULTS}

\section{Feeding and Social Behaviors}

Before calving, we found no differences between healthy cows and cows later diagnosed with metritis for any feeding or social behavior measure (Table 1); however, during the $3 \mathrm{~d}$ before metritis diagnosis, metritic cows ate approximately $1 \mathrm{~kg} / \mathrm{d}$ less (Figure 1a; $F_{1,169}=$ 9.88, $P<0.01$ ) and consumed fewer meals (Figure $1 \mathrm{~b}$; $\left.F_{1,169}=6.54, P<0.05\right)$ compared with healthy cows. Health status and day of diagnosis tended to interact $(P$ $=0.07$ ), with cows diagnosed closer to calving showing a greater decrease in the number of meals before diagnosis (Figure $1 \mathrm{~b}$ ). In the $3 \mathrm{~d}$ before diagnosis, metritic cows were more often replaced at the feed bunk than healthy cows $\left(F_{1,169}=4.05, P=0.05\right)$. We observed no differences between metritic and healthy cows during the $3 \mathrm{~d}$ before metritis diagnosis for other measures of feeding behavior (time spent feeding, number of visits, or feeding rate).

When cows that were later diagnosed with both metritis and subclinical ketosis were included in the metritis population, these animals ate less $\left(F_{1,181}=15.26\right.$, $P<0.001)$, had fewer visits to the feed bunk $\left(F_{1,181}=\right.$ 3.68, $P=0.05)$, tended to have a lower feeding rate $\left(F_{1,181}=3.57, P=0.06\right)$, and consumed fewer meals $\left(F_{1,181}=6.09, P<0.05\right)$ compared with healthy cows in the $3 \mathrm{~d}$ before metritis diagnosis (Table 1). For this population of cows, we also found no differences during the $3 \mathrm{~d}$ before metritis diagnosis or during the prepartum period for other measures of feeding behavior.

\section{Lying Behaviors}

Cows later diagnosed with metritis spent less time lying down before calving in wk $-2\left(F_{1,140}=4.30, P<\right.$ $0.05)$ and $-1\left(F_{1,148}=10.93, P<0.01\right)$, and had fewer lying bouts during wk $-2\left(F_{1,140}=5.59, P<0.05\right)$ and $-1\left(F_{1,148}=5.65, P<0.05 ;\right.$ Table 1$)$. Healthy cows and those later diagnosed with metritis did not differ in lying bout duration before calving. In the $3 \mathrm{~d}$ before 
Table 1. Prediagnosis feeding, social, and lying behavior measures (LSM \pm SE) for healthy $(\mathrm{n}=98)$, metritic only ( score $3, \mathrm{n}=21$; score $4, \mathrm{n}=53$ ), and metritic or metritic plus subclincially ketotic (SCK; score $3, \mathrm{n}=$ 23; score $4, \mathrm{n}=63$ ) Holstein dairy cows during the $2 \mathrm{wk}$ before calving (wk -2 and -1 ) and the $3 \mathrm{~d}$ before metritis diagnosis

\begin{tabular}{|c|c|c|c|}
\hline \multirow[b]{3}{*}{ Variable } & \multicolumn{3}{|c|}{ Period } \\
\hline & \multicolumn{2}{|c|}{ Before calving } & \multirow{2}{*}{$\begin{array}{c}\text { After calving } \\
\begin{array}{c}\text { Mean of d 1-3 } \\
\text { before diagnosis }\end{array}\end{array}$} \\
\hline & wk -2 & wk -1 & \\
\hline \multicolumn{4}{|l|}{ Feeding behavior } \\
\hline \multicolumn{4}{|l|}{ DMI $(\mathrm{kg} / \mathrm{d})$} \\
\hline Healthy & $14.6 \pm 0.2$ & $13.6 \pm 0.2$ & $16.9 \pm 0.2^{\mathrm{a}}$ \\
\hline Metritic only & $14.8 \pm 0.2$ & $13.5 \pm 0.2$ & $15.8 \pm 0.4^{\mathrm{b}}$ \\
\hline Metritic or Metritic + SCK & $14.5 \pm 0.2$ & $13.1 \pm 0.2$ & $15.3 \pm 0.3^{\mathrm{b}}$ \\
\hline \multicolumn{4}{|l|}{ Time spent feeding $(\min / \mathrm{d})$} \\
\hline Healthy & $227.4 \pm 4.1$ & $204.8 \pm 3.8$ & $166.8 \pm 2.8$ \\
\hline Metritic only & $235.9 \pm 4.8$ & $210.4 \pm 4.4$ & $165.3 \pm 4.3$ \\
\hline Metritic or Metritic + SCK & $231.2 \pm 4.5$ & $203.8 \pm 4.2$ & $161.3 \pm 4.0$ \\
\hline \multicolumn{4}{|l|}{ Feed bin visits (no./d) } \\
\hline Healthy & $80.4 \pm 2.0$ & $74.4 \pm 1.9$ & $56.7 \pm 1.4^{\mathrm{a}}$ \\
\hline Metritic only & $82.0 \pm 2.3$ & $75.7 \pm 2.2$ & $53.7 \pm 1.9^{\mathrm{ab}}$ \\
\hline Metritic or Metritic + SCK & $80.4 \pm 2.2$ & $73.4 \pm 2.1$ & $52.3 \pm 1.8^{\mathrm{b}}$ \\
\hline \multicolumn{4}{|l|}{ Feeding rate $(\mathrm{g}$ of $\mathrm{DM} / \mathrm{min})$} \\
\hline Healthy & $74.2 \pm 1.3$ & $76.4 \pm 1.2$ & $109.1 \pm 1.7^{\mathrm{a}}$ \\
\hline Metritic only & $72.2 \pm 1.5$ & $74.3 \pm 1.4$ & $104.7 \pm 2.3^{\mathrm{ab}}$ \\
\hline Metritic or Metritic + SCK & $72.1 \pm 1.4$ & $74.5 \pm 1.3$ & $104.0 \pm 2.2^{\mathrm{b}}$ \\
\hline \multicolumn{4}{|l|}{ Meals (no./d) } \\
\hline Healthy & $6.1 \pm 0.1$ & $6.6 \pm 0.1$ & $8.5 \pm 0.1^{\mathrm{a}}$ \\
\hline Metritic only & $5.9 \pm 0.1$ & $6.4 \pm 0.2$ & $8.1 \pm 0.2^{\mathrm{b}}$ \\
\hline Metritic or Metritic + SCK & $5.9 \pm 0.1$ & $6.5 \pm 0.2$ & $8.1 \pm 0.2^{\mathrm{b}}$ \\
\hline \multicolumn{4}{|l|}{ Bins visited per meal (no./d) } \\
\hline Healthy & $5.0 \pm 0.1$ & $4.6 \pm 0.1$ & $3.9 \pm 0.05$ \\
\hline Metritic only & $5.2 \pm 0.1$ & $4.8 \pm 0.1$ & $3.9 \pm 0.09$ \\
\hline Metritic or Metritic + SCK & $5.1 \pm 0.1$ & $4.6 \pm 0.1$ & $3.8 \pm 0.08$ \\
\hline \multicolumn{4}{|c|}{ Social behavior } \\
\hline \multicolumn{4}{|c|}{ Actor replacements per visit (no./d) } \\
\hline Healthy & $0.31 \pm 0.01$ & $0.32 \pm 0.01$ & $0.20 \pm 0.007$ \\
\hline Metritic only & $0.33 \pm 0.01$ & $0.34 \pm 0.01$ & $0.20 \pm 0.01$ \\
\hline Metritic or Metritic + SCK & $0.33 \pm 0.01$ & $0.33 \pm 0.01$ & $0.20 \pm 0.01$ \\
\hline \multicolumn{4}{|c|}{ Reactor replacements per visit (no./d) } \\
\hline Healthy & $0.32 \pm 0.01$ & $0.30 \pm 0.01$ & $0.21 \pm 0.006^{\mathrm{a}}$ \\
\hline Metritic only & $0.32 \pm 0.01$ & $0.32 \pm 0.01$ & $0.23 \pm 0.009^{\mathrm{b}}$ \\
\hline Metritic or Metritic + SCK & $0.32 \pm 0.01$ & $0.31 \pm 0.01$ & $0.23 \pm 0.009^{\mathrm{ab}}$ \\
\hline \multicolumn{4}{|l|}{ Lying behavior } \\
\hline \multicolumn{4}{|l|}{ Lving time $(\mathrm{min} / \mathrm{d})$} \\
\hline Healthy & $713.7 \pm 12.4^{\mathrm{a}}$ & $654.3 \pm 12.8^{\mathrm{a}}$ & $608.7 \pm 10.4$ \\
\hline Metritic only & $673.5 \pm 14.6^{\mathrm{b}}$ & $588.9 \pm 14.8^{\mathrm{b}}$ & $591.5 \pm 15.0$ \\
\hline Metritic or Metritic + SCK & $673.5 \pm 14.6^{\mathrm{b}}$ & $588.9 \pm 14.8^{\mathrm{b}}$ & $591.5 \pm 15.0$ \\
\hline \multicolumn{4}{|l|}{ Lying bouts (no./d) } \\
\hline Healthy & $11.5 \pm 0.3^{\mathrm{a}}$ & $12.4 \pm 0.4^{\mathrm{a}}$ & $12.9 \pm 0.3^{\mathrm{a}}$ \\
\hline Metritic only & $10.5 \pm 0.3^{\mathrm{b}}$ & $11.0 \pm 0.4^{\mathrm{b}}$ & $11.5 \pm 0.4^{\mathrm{b}}$ \\
\hline Metritic or Metritic + SCK & $10.5 \pm 0.3^{\mathrm{b}}$ & $11.0 \pm 0.4^{\mathrm{b}}$ & $11.5 \pm 0.4^{\mathrm{b}}$ \\
\hline \multicolumn{4}{|l|}{ Lying bout duration (min/bout) } \\
\hline Healthy & $66.9 \pm 1.6$ & $59.7 \pm 1.8$ & $54.2 \pm 1.2^{\mathrm{a}}$ \\
\hline Metritic only & $69.2 \pm 1.9$ & $60.8 \pm 2.1$ & $59.2 \pm 1.9^{\mathrm{b}}$ \\
\hline Metritic or Metritic + SCK & $69.2 \pm 1.9$ & $60.8 \pm 2.1$ & $59.2 \pm 1.9^{\mathrm{b}}$ \\
\hline
\end{tabular}

$\overline{\mathrm{a}, \mathrm{b}}$ Different superscripts within a column indicate significant difference $(P \leq 0.05)$ between health categories.

diagnosis, metritic cows had fewer $\left(F_{1,162}=6.68, P<\right.$ $0.05)$ and longer $\left(F_{1.162}=4.92, P<0.05\right)$ lying bouts. We observed no difference in lying time compared with healthy cows; these results did not change when cows with both metritis and subclinical ketosis were included in the metritis population (Table 1).

\section{DISCUSSION}

\section{Feeding Behavior}

Our results showed modest changes in feeding, social, and lying behaviors in the days before metritis diag- 


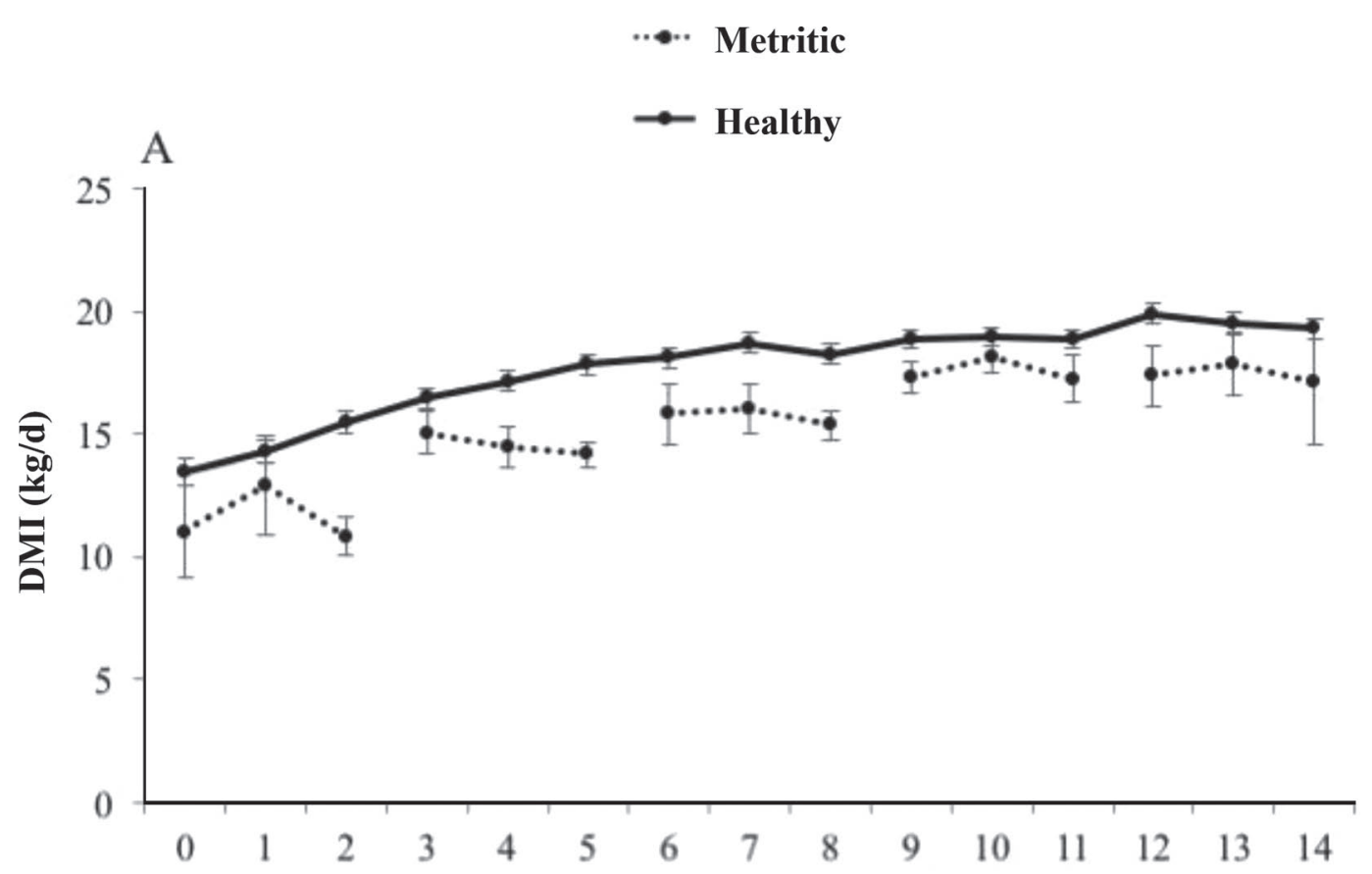

B

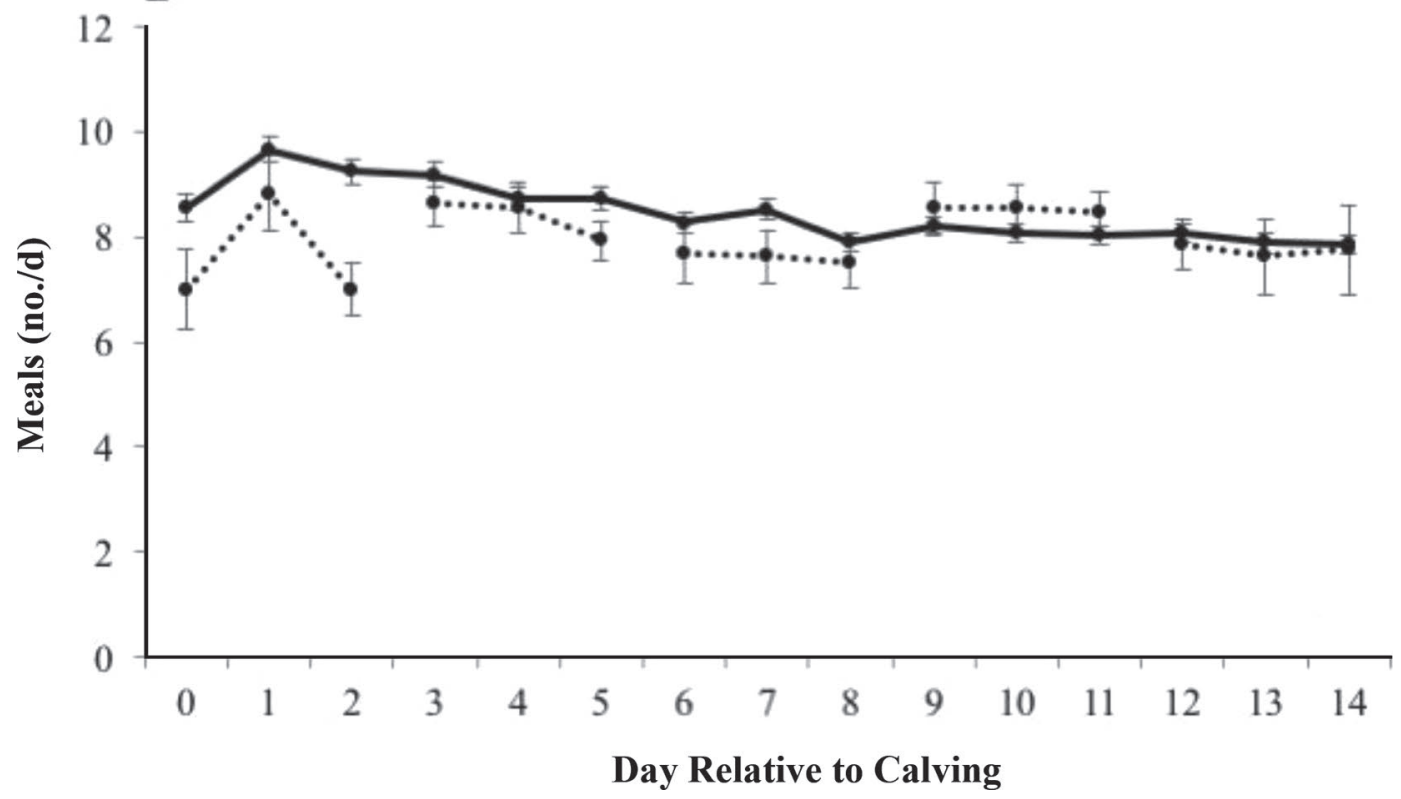

Figure 1. Arithmetic mean $( \pm \mathrm{SE})$ of (a) DMI ( $\mathrm{kg}$ of DM/d) or (b) number of meals consumed (no./d) during the $3 \mathrm{~d}$ before diagnosis with metritis on d $3(\mathrm{n}=7), 6(\mathrm{n}=32), 9(\mathrm{n}=16), 12(\mathrm{n}=11)$, and $15(\mathrm{n}=8)$ in comparison with data from healthy cows $(\mathrm{n}=98)$ on these same 3 -d periods after calving.

nosis (summarized in Table 2). A key finding was that cows that were diagnosed with metritis ate about $1 \mathrm{~kg}$ less per day and ate fewer meals during the $3 \mathrm{~d}$ before diagnosis. The difference in meals was greatest when cows were diagnosed close to calving.
Our results are consistent with the results from an earlier study from the same facility (Huzzey et al., 2007), and from another study from a different facility (Bareille et al., 2003); all 3 studies report changes in feeding behavior in the days before metritis diag- 
Table 2. Summary of behavioral differences between healthy $(\mathrm{n}=98)$, metritic only cows $(\mathrm{n}=74)$, and metritic plus subclinically ketotic $(\mathrm{SCK} ; \mathrm{n}=86)$

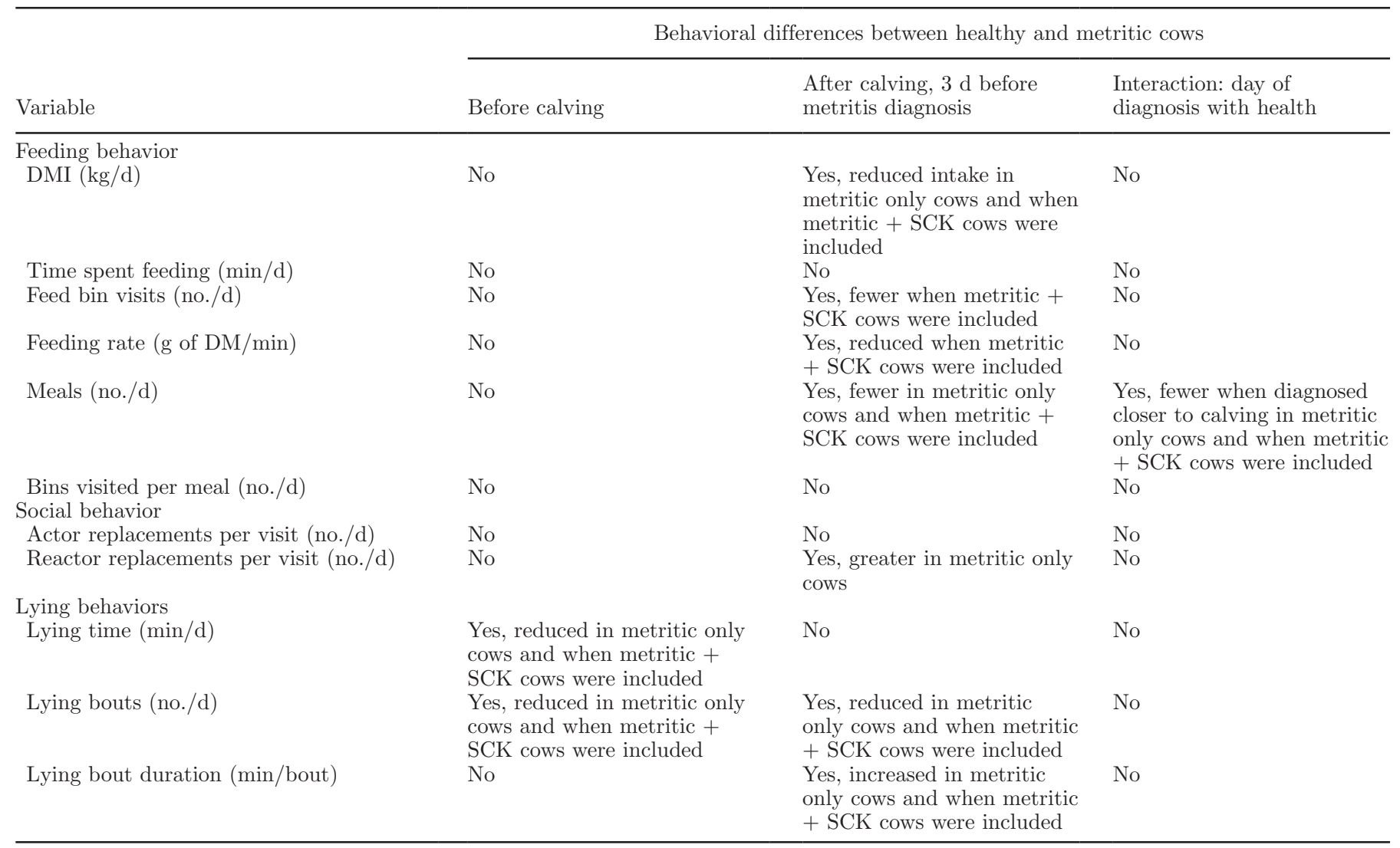

nosis. Other studies have reported changes in feeding behavior in the days before diagnosis of other health disorders (e.g., mastitis, Sepúlveda-Varas et al., 2016; ketosis, González et al., 2008). Reduced feeding is commonly used as an indicator of illness and may be seen even before clinical symptoms of illness appear (Weary et al., 2009). Reduced intake may be driven by several different mechanisms, including low motivation to seek food due to loss of appetite. Sick animals may conserve energy by remaining idle rather than expending energy by foraging for food (Hart, 1988). Sick cows may also limit feeder visits to avoid engaging in agonistic encounters that may be required to secure access to fresh feed (Huzzey et al., 2006), or they may have elected to remain lying due to increased motivation for rest or sleep, which may combat the feelings of malaise (Millman, 2007).

Studies on other transition period health disorders have also shown reduced feeding time (ketosis: González et al., 2008; Goldhawk et al., 2009) and feed bunk visits (ketosis: Goldhawk et al., 2009; mastitis: Sepúlveda-Varas et al., 2016). Similar to the present study, Sepúlveda-Varas et al. (2016) reported a decline in feed intake in the days before diagnosis with mastitis that was mainly driven by a decline in feeding rate rather than in feeding time. The different ways in which feeding behaviors are affected by transition cow health disorders was discussed by González et al. (2008), who showed that cows with ketosis had changes in feeding time, feed bunk visits, and feeding rate, lame cows had increased feeding rate, and cows with mastitis showed large variation in their behavioral responses. The cows in our study had reduced feed intake before visible clinical symptoms of metritis, but only cows subsequently diagnosed as having both metritis and ketosis had reduced visits to the feed bunk. This suggests that a combination of metritis and ketosis, rather than metritis illness alone, may result in greater malaise leading to more pronounced avoidance of competition at the feeding area.

Huzzey et al. (2007) reported differences in feeding behavior in the weeks before calving in cows that later developed metritis. In the current study, we were unable to replicate these findings when considering only cows 
with metritis and no other health disorder. However, for Huzzey et al. (2007), the metritic category included cows that had other health disorders, including ketosis and lameness, potentially accentuating behavioral differences between these cows and healthy cows. When we included into our metritic group cows that were later diagnosed with both metritis and subclinical ketosis differences in DMI, visits and feeding rate became more pronounced, suggesting that ketosis may be a driver of these behavioral differences. Other work has shown that cows with subclinical ketosis exhibit changes in feeding behavior (Goldhawk et al., 2009) and standing behavior (Itle et al., 2015) before diagnosis. Hammon et al. (2006) reported that cows diagnosed with puerperal metritis or subclinical endometritis had reduced DMI beginning the week before calving; however, these cows also had elevated nonesterified fatty acid levels beginning 2 wk before calving and higher BHB during wk 1 to 4 after calving, suggesting that differences in feeding behaviors before calving could be due to early signs of ketosis rather than to metritis itself. Other work (Sepúlveda-Varas et al., 2014) has shown that behavioral differences between healthy and sick animals are greater when cows are affected by multiple health disorders.

Differences in the composition of the prepartum diet may have accentuated these effects. Huzzey et al. (2007) fed dry cows a lower-energy ( $14 \%$ concentrate) far-off diet and then switched to a higher-energy (36\% concentrate) close-up diet starting 3 wk before calving; cows in the current study remained on a lower-energy (14\% concentrate) diet throughout the dry period. Schirmann et al. (2016) used the same feeding regimen as in the current study and also reported no prepartum DMI differences in feeding behavior between cows later diagnosed with metritis and cows that remained healthy. The use of a single higher-forage and lowerenergy dry cow diet is associated with decreased risk of subclinical ketosis after calving (Vickers et al., 2013). This difference in diet likely placed the cows in Huzzey et al. (2007) at greater risk of ketosis, increasing the chance that differences they observed were due to ketosis.

\section{Lying Behavior}

We found that cows later diagnosed with metritis spent less time lying and had fewer lying bouts in the 2 wk before calving, and had fewer lying bouts and longer bout duration in the $3 \mathrm{~d}$ before diagnosis with metritis compared with healthy cows. Whereas we found no increase in lying time in the days before diagnosis, our results suggest that cows may be conserving energy by lying down for longer, resulting in fewer bouts throughout the day. A recent study showed that lying time increased in cows after metritis diagnosis (Barragan et al., 2016); perhaps lying time is affected only after clinical symptoms of metritis become apparent. Similar changes in lying behavior before diagnosis were found in cows with clinical ketosis; these cows spent less time lying in the week before calving and had fewer lying bouts on the day of calving (Itle et al., 2015). However, Kaufman et al. (2016) reported no differences in lying time, number of bouts, or bout duration before diagnosis of ketosis. Sepúlveda-Varas et al. (2014) also found that primiparous cows diagnosed with more than 1 clinical health disorder tended to have longer lying bouts on d 3 and 4 after calving compared with healthy cows. Cows with mastitis also had decreased lying time, possibly in reaction to painful pressure on the udder when lying (Fogsgaard et al., 2012). Collectively, this research indicates that lying behavior may be affected before, during, or after the onset of a health disorder, but similar to the feeding behavior results described above, the way in which lying varies with illness is likely dependent upon the nature of the ailment.

A decrease in lying time, or, by definition, an increase in standing time, may be a consequence of engaging in other behaviors, such as competitive behaviors at the feed bunk. Cows later diagnosed with metritis were found to be just as competitive as healthy cows at the feed bunk before calving. These cows may have also competed for desirable lying spaces, although this was not measured in our study. Other studies have reported increased time standing inactive before calving and before diagnosis with metritis (Patbandha et al., 2012), subclinical hypocalcemia (Jawor et al., 2012), or clinical ketosis (Itle et al., 2015). These energetically costly behaviors may have compromised the immune system, making the animal more susceptible to infection. Alternatively, the decreased lying time may have been in response to an undiagnosed prepartum ailment (other than lameness; health was not systematically monitored prepartum), and this condition might have increased the risk of the animal developing metritis. Experimental work is required to better understand the causal links between these behaviors and illness.

\section{Social Behavior}

There are several reasons to expect differences in social behavior between sick and healthy cows: the behavior of dairy cows is influenced by the social environment (Nielsen, 1999), social stressors can increase the risk of illness (reviewed by Proudfoot et al., 2012; Proudfoot and Habing, 2015), and cows are known to 
isolate themselves from the herd when sick (Proudfoot et al., 2014). This latter behavior may serve a biological function of avoiding pathogen transfer from or to group mates (Loehle, 1995). Alternatively, social avoidance may be a means of avoiding agonistic interactions; for example, Cohn and de Sá-Rocha (2006) showed that dominant rats administered LPS decreased their agonistic behaviors whereas more subordinate rats did not, perhaps because socially defensive behaviors are a way for low-status individuals to limit injury as opposed to submitting to offensive behavior. Our study did not find changes in agonistic actor replacements (where a metritic cow displaced another feeding cow and took her place at the feed bin), but our social behavior measure was limited to feed bunk replacements, which only included cases where a cow physically removed and immediately took another cow's place at the feed bunk. Because we collected this replacement data electronically, we were unable to record cases of displacement in which a cow physically removed another cow from the feed bunk but did not take her place at the feed bunk, or cases where a cow was not successful in her attempt to displace another cow. This displacementwithout-replacement behavior could be considered more agonistic in nature because the displacing cow had no apparent motive to consume feed from that particular bin at the time of displacement. Following evidence in rodents (Cohn and de Sá-Rocha, 2006), social hierarchy may play a role in the expression of sickness behavior in cows; further research should investigate if dominant cows are more likely to reduce agonistic interactions when they are sick.

Other studies have reported changes in social behaviors before the diagnosis of other transition cow health disorders. Sick cows engaged in fewer competitive displacements in the weeks before diagnosis of ketosis (Goldhawk et al., 2009) and metritis (Huzzey et al., 2007). Sepúlveda-Varas et al. (2016) used the same methodology as the present study to measure replacements at the feed bin and found that mastitic cows had fewer replacements in the $5 \mathrm{~d}$ before diagnosis. Neither of these studies reported cases of reactor replacement, in which a cow was removed from the feed bin. To our knowledge, our study is the first to show that metritic cows were replaced more often at the feed bunk (i.e., were the recipient of the agonistic interaction) in the 3 $\mathrm{d}$ before diagnosis. Cows in our study were overstocked at the feed bins (12 bins for 20 cows), adding an additional social stressor where metritic animals may have been unable or unwilling to hold their place at the feed bunk, which made them more susceptible to being replaced. Alternatively, increased replacements may have predisposed these individuals to illness.

\section{Metritis Severity}

We found no difference in the behavioral responses of cows with different severity scores of metritis. Huzzey et al. (2007) found a greater decrease in DMI and feeding time for severely metritic cows (score 4 with fever) compared with mildly metritic cows (score 2 or 3 , with or without fever). Urton et al. (2005) also found that cows with more severe cases (score 4 with fever) had decreased feeding time before calving compared with cows with score 2 or 3 with fever. We did not consider fever in our classification, as preliminary analyses suggested that adding fever provided no additional explanatory value. We did not have a large enough sample size to meaningfully test behavioral differences between metritic cows with and without fever for each of score 3 and 4 .

\section{CONCLUSIONS}

Changes in feeding, social, and lying behavior can contribute to identification of cows at risk of metritis. We also provide the first evidence that some behavioral changes associated with metritis are more pronounced when diagnosed closer to calving. These behaviors, which are observed before other clinical symptoms of metritis appear, may predispose cows to illness or may be a suite of behaviors expressed at the early stages of illness; the causal links between behavior and illness remain to be understood.

\section{ACKNOWLEDGMENTS}

We thank all the staff and students of the UBC Dairy Education and Research Centre (Agassiz, BC, Canada) who helped with data collection in this experiment, and Joao H. Cardoso Costa (University of British Columbia) for his assistance with statistical analysis and comments on the previous version of this manuscript. We thank Boehringer Ingelheim Inc. (Guelph, ON, Canada) for their generous donation to support the various students that helped with this trial. H. W. Neave is supported by Canada's Natural Sciences and Engineering Research Council (NSERC, Ottawa, ON, Canada) Canadian Graduate Scholarship. M. A. G. von Keyserlingk and D. M. Weary are supported by Canada's Natural Sciences and Engineering Research Council (NSERC) Industrial Research Chair Program with industry contributions from the Dairy Farmers of Canada (Ottawa, ON, Canada), British Columbia Dairy Association (Burnaby, BC, Canada), Westgen Endowment Fund (Milner, BC, Canada), Intervet Canada Corporation (Kirkland, QC, Canada), Novus Interna- 
tional Inc. (Oakville, ON, Canada), Zoetis (Kirkland, QC, Canada), BC Cattle Industry Development Fund (Kamloops, BC, Canada), Alberta Milk (Edmonton, AB, Canada), Valacta (St. Anne-de-Bellevue, QC, Canada), and CanWest DHI (Guelph, ON, Canada).

\section{REFERENCES}

Bach, A., M. Dinares, M. Devant, and X. Carré. 2007. Associations between lameness and production, feeding and milking attendance of Holstein cows milked with an automatic milking system. J. Dairy Res. 74:40.

Bareille, N., F. Beaudeau, S. Billon, A. Robert, and P. Faverdin. 2003. Effects of health disorders on feed intake and milk production in dairy cows. Livest. Prod. Sci. 83:53-62.

Barragan, A. A., S. Bas, J. M. Piñeiro, G. M. Schuenemann, P. RajalaSchultz, and D. Sanders. 2016. Assessment of biomarkers of pain and daily activity patterns in lactating dairy cows diagnosed with clinical metritis. J. Anim. Sci. 94(Suppl. 5):34-35.

CCAC (Canadian Council On Animal Care). 2009. The care and use of farm animals in research, teaching and testing. CCAC, Ottawa, ON, Canada.

Chapinal, N., D. M. Veira, D. M. Weary, and M. A. G. von Keyserlingk. 2007. Technical note: Validation of a system for monitoring individual feeding and drinking behavior and intake in grouphoused cattle. J. Dairy Sci. 90:5732-5736.

Cohn, D. W. H., and L. C. de Sá-Rocha. 2006. Differential effects of lipopolysaccharide in the social behavior of dominant and submissive mice. Physiol. Behav. 87:932-937.

Esposito, G., P. C. Irons, E. C. Webb, and A. Chapwanya. 2014. Interactions between negative energy balance, metabolic diseases, uterine health and immune response in transition dairy cows. Anim. Reprod. Sci. 144:60-71.

Flower, F. C., and D. M. Weary. 2006. Effect of hoof pathologies on subjective assessments of dairy cow gait. J. Dairy Sci. 89:139-146.

Fogsgaard, K. K., C. M. Røntved, P. Sørensen, and M. S. Herskin. 2012. Sickness behavior in dairy cows during Escherichia coli mastitis. J. Dairy Sci. 95:630-638.

Forbes, A. B. C. A. Huckle, and M. J. Gibb. 2004. Impact of eprinomectin on grazing behaviour and performance in dairy cattle with sub-clinical gastrointestinal nematode infections under continuous stocking management. Vet. Parasitol. 125:353-364.

Goldhawk, C., N. Chapinal, D. M. Veira, D. M. Weary, and M. A G. von Keyserlingk. 2009. Prepartum feeding behavior is an early indicator of subclinical ketosis. J. Dairy Sci. 92:4971-4977.

González, L. A., B. J. Tolkamp, M. P. Coffey, A. Ferret, and I. Kyriazakis. 2008. Changes in feeding behavior as possible indicators for the automatic monitoring of health disorders in dairy cows. J. Dairy Sci. 91:1017-1028.

Hammon, D. S., I. M. Evjen, T. R. Dhiman, J. P. Goff, and J. L. Walters. 2006. Neutrophil function and energy status in Holstein cows with uterine health disorders. Vet. Immunol. Immunopathol. 113:21-29.

Hart, B. L. 1988. Biological basis of the behavior of sick animals. Neurosci. Biobehav. Rev. 12:123-137.

Huzzey, J. M., T. J. DeVries, P. Valois, and M. A. G. Von Keyserlingk. 2006. Stocking density and feed barrier design affect the feeding and social behavior of dairy cattle. J. Dairy Sci. 89:126-133.

Huzzey, J. M., D. M. Veira, D. M. Weary, and M. A. G. von Keyserlingk. 2007. Prepartum behavior and dry matter intake identify dairy cows at risk for metritis. J. Dairy Sci. 90:3220-3233.

Huzzey, J. M., D. M. Weary, B. Y. F. Tiau, and M. A. G. von Keyserlingk. 2014. Short communication: Automatic detection of social competition using an electronic feeding system. J. Dairy Sci. 97:2953-2958.

Itle, A. J., J. M. Huzzey, D. M. Weary, and M. A. G. von Keyserlingk 2015. Clinical ketosis and standing behavior in transition cows. J. Dairy Sci. 98:128-134.
Ito, K., D. M. Weary, and M. A. G. von Keyserlingk. 2009. Lying behavior: Assessing within- and between-herd variation in free-stallhoused dairy cows. J. Dairy Sci. 92:4412-4420.

Jawor, P. E., J. M. Huzzey, S. J. LeBlanc, and M. A. G. von Keyserlingk. 2012. Associations of subclinical hypocalcemia at calving with milk yield, and feeding, drinking, and standing behaviors around parturition in Holstein cows. J. Dairy Sci. 95:1240-1248.

Kaufman, E. I., S. J. LeBlanc, B. W. McBride, T. F. Duffield, and T. J. DeVries. 2016. Short communication: Association of lying behavior and subclinical ketosis in transition dairy cows. J. Dairy Sci. 99:7473-7480.

LeBlanc, S. 2010. Monitoring metabolic health of dairy cattle in the transition period. J. Reprod. Dev. 56:S29-S35.

Loehle, C. 1995. Social barriers to pathogen transmission in wild animal populations. Ecology 76:326.

Lomb, J., H. W. Neave, D. M. Weary, S. J. LeBlanc, J. M. Huzzey, and M. A. G. von Keyserlingk. 2018. Changes in feeding, social, and lying behaviors in dairy cows with metritis following treatment with a nonsteroidal anti-inflammatory drug as adjunctive treatment to an antimicrobial. J. Dairy Sci. 101:4400-4411. https://doi.org/10 $.3168 /$ jds.2017-13812.

Millman, S. T. 2007. Sickness behaviour and its relevance to animal welfare assessment at the group level. Anim. Welf. 16:123-125.

NRC. 2001. Nutrient Requirements of Dairy Cattle. 7th rev. ed. Natl. Acad. Press, Washington, DC.

Neave, H. W., J. Lomb, M. A. G. von Keyserlingk, A. Behnam-Shabahang, and D. M. Weary. 2017. Parity differences in the behavior of transition dairy cows. J. Dairy Sci. 100:548-561.

Nielsen, B. L. 1999. On the interpretation of feeding behaviour measures and the use of feeding rate as an indicator of social constraint. Appl. Anim. Behav. Sci. 63:79-91.

Patbandha, T. K., T. K. Mohanty, S. S. Layek, A. Kumaresan, and K. Behera. 2012. Application of pre-partum feeding and social behaviour in predicting risk of developing metritis in crossbred cows. Appl. Anim. Behav. Sci. 139:10-17.

Proudfoot, K., and G. Habing. 2015. Social stress as a cause of disease in farm animals: current knowledge and future directions. Vet. J. $206: 15-21$.

Proudfoot, K. L., M. B. Jensen, P. M. H. Heegaard, and M. A. G. von Keyserlingk. 2013. Effect of moving dairy cows at different stages of labor on behavior during parturition. J. Dairy Sci. 96:1638-1646.

Proudfoot, K. L., M. B. Jensen, D. M. Weary, and M. A. G. von Keyserlingk. 2014. Dairy cows seek isolation at calving and when ill. J. Dairy Sci. 97:2731-2739.

Proudfoot, K. L., D. M. Veira, D. M. Weary, and M. A. G. von Keyserlingk. 2009. Competition at the feed bunk changes the feeding, standing, and social behavior of transition dairy cows. J. Dairy Sci. 92:3116-3123.

Proudfoot, K. L., D. M. Weary, and M. A. G. von Keyserlingk. 2012 Linking the social environment to illness in farm animals. Appl. Anim. Behav. Sci. 138:203-215.

Schirmann, K., D. M. Weary, W. Heuwieser, N. Chapinal, R. L. A Cerri, and M. A. G. von Keyserlingk. 2016. Short communication: Rumination and feeding behaviors differ between healthy and sick dairy cows during the transition period. J. Dairy Sci. 99:9917-9924

Sepúlveda-Varas, P., K. L. Proudfoot, D. M. Weary, and M. A. G. von Keyserlingk. 2016. Changes in behavior of dairy cows with clinical mastitis. Appl. Anim. Behav. Sci. 175:8-13.

Sepúlveda-Varas, P., D. M. Weary, and M. A. G. von Keyserlingk. 2014. Lying behavior and postpartum health status in grazing dairy cows. J. Dairy Sci. 97:6334-6343.

Sheldon, I. M., G. S. Lewis, S. LeBlanc, and R. O. Gilbert. 2006. Defining postpartum uterine disease in cattle. Theriogenology 65:1516-1530

Sheldon, I. M., E. J. Williams, A. N. A. Miller, D. M. Nash, and S. Herath. 2008. Uterine diseases in cattle after parturition. Vet. J. $176: 115-121$.

Szyszka, O., B. J. Tolkamp, S. A. Edwards, and I. Kyriazakis. 2013. Do the changes in the behaviours of cattle during parasitism with 
Ostertagia ostertagi have a potential diagnostic value? Vet. Parasitol. 193:214-222.

Työppönen, J., and K. Kauppinen. 1980. Stability and automatic determination of ketone bodies in blood samples taken [from cattle] in field conditions. Acta Vet. Scand. 21:55-61.

UBC Animal Welfare Program. 2013. SOP-HOBO Data Loggers. University of British Columbia, Vancouver, Canada. Accessed May 28, 2017. http://lfs-awp.sites.olt.ubc.ca/files/2013/11/SOP -HOBO-Datalogger-november-2013.pdf.

Urton, G., M. A. G. von Keyserlingk, and D. M. Weary. 2005. Feeding behavior identifies dairy cows at risk for metritis. J. Dairy Sci. 88:2843-2849.
Vickers, L. A., D. M. Weary, D. M. Veira, and M. A. G. von Keyserlingk. 2013. Feeding a higher forage diet prepartum decreases incidences of subclinical ketosis in transition dairy cows. J. Anim. Sci. 91:886-894.

Weary, D. M., J. M. Huzzey, and M. A. G. Von Keyserlingk. 2009. Board-invited review: Using behavior to predict and identify ill health in animals. J. Anim. Sci. 87:770-777.

Zobel, G., D. M. Weary, K. Leslie, N. Chapinal, and M. A. G. von Keyserlingk. 2015. Technical note: Validation of data loggers for recording lying behavior in dairy goats. J. Dairy Sci. 98:1082-1089. 